Res Mobilis

Revista internacional de investigación en mobiliario y

objetos decorativos

Vol. 4, nº 4, 2015

\title{
CERVIGÓN: LUJO ART DÉCO EN GALICIA \\ CERVIGÓN: LUXURY ART DÉCO IN GALICIA
}

Isabel Barro Rey*

Universidad de Oviedo

\section{Resumen}

A mediados del siglo XIX, la familia Cervigón comienza su trayectoria empresarial en el comercio y transformación de la madera, pero con el cambio de siglo las nuevas generaciones dieron un especial impulso a la fabricación y venta de muebles, llegando a ser uno de los nombres de referencia del sector en A Coruña. La Exposición Internacional de Artes Decorativas de París de 1925 inspiraría su producción de muebles de lujo, que constituye uno de los escasos ejemplos de Art Déco en Galicia y de la cual veremos una obra.

Palabras Clave: Art Déco, muebles de lujo, Cervigón, decoración, Galicia.

\section{Abstract}

In mid-19th century, the Cervigón family starts its business career in the trade and processing of wood, but with the turn of the century the new generations gave a special boost to the manufacture and selling of furniture, becoming one of the reference names of this sector in A Coruña. The International Exhibition of Decorative Arts in Paris, 1925 inspired their production of luxury furniture, which constitutes one of the scarce examples of Art Déco in Galicia and of which we will study a particular work.

Keywords: Art Déco, luxury furniture, Cervigón, interior design, Galicia.

En la segunda década del siglo XX, Manuel Andrade, miembro de la burguesía de A Coruña, construye un edificio de viviendas de lujo destinadas a uso familiar en el Cantón Pequeño, un céntrico paseo frente al puerto y junto al ensanche moderno ${ }^{1}$. Uno de los hijos del propietario contrae matrimonio en 1931 y se instala con su esposa en una de estas viviendas. Para amueblar el comedor, el dormitorio y el despacho -los espacios más significativos de su nuevo hogar-

\footnotetext{
* Becaria de Ficyt, E-mail: isabarrey@gmail.com
} 
recurren a la casa Hijos de Emilio Cervigón Carreras por la calidad de las maderas que utilizaba y por su reputación como ebanistas ${ }^{2}$. En poco más de una década, la empresa había pasado de ser conocida por su aserradero de Riazor a convertirse en el referente de muebles de lujo en A Coruña.

\section{La familia Cervigón y la madera}

El origen de esta empresa familiar está vinculado a Eduardo Marcelino Cervigón Aldao, quien, tras morir sus padres en 1860, se sitúa al frente del negocio mercantil familiar junto a su hermano Esteban ${ }^{3}$. Inquieto y visionario, descubrió el alambre en una de las exposiciones universales a las que solía acudir y abrió una innovadora fábrica de clavos de hierro y puntas de París en A Coruña, que pronto ampliaría con tienda de ferretería y carpintería en el número 23 de la calle Real. Extendió a la madera la actividad importadora y exportadora heredada de su padre, de tal modo que, con el aserradero que poseía junto a la playa, abarcaba todo el ciclo de este producto ${ }^{4}$. Pero su imparable actividad empresarial abarcó también otras áreas, como el refinado y venta de petróleo, fábrica de sombreros, inversiones en bienes raíces y negocios financieros ${ }^{5}$. (Fig. 1)

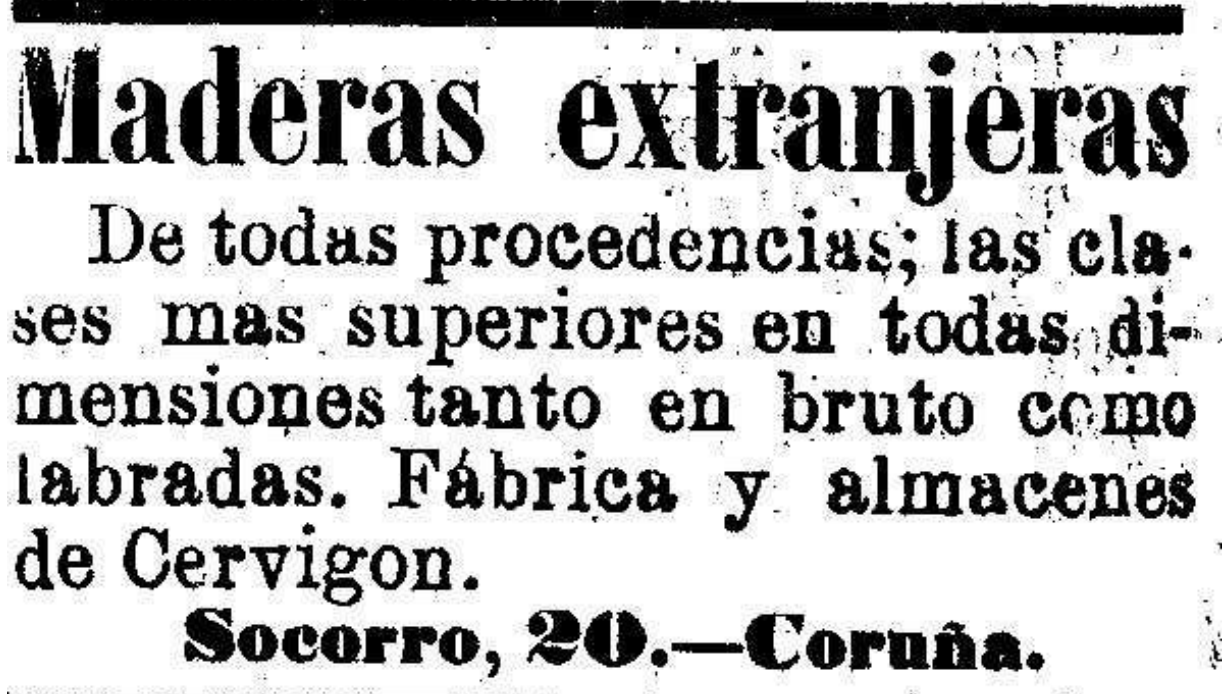

Fig. 1. Anuncio publicado en La Voz de Galicia el 4 de marzo de 1883.

En 1909 sus hijos, Arturo y Emilio Cervigón Carreras, fundaron la sociedad Hijos de Eduardo M. Cervigón, centrada ya de lleno en el pujante sector maderero. Consiguieron aumentar las importaciones y exportaciones en toda la gama de maderas, modernizaron y ampliaron el aserradero y el taller y, como novedad, incorporaron la división de fabricación de muebles, que se vendían en el nuevo local de la calle Real 47, donde también disponían de un taller dorador de madera. Con esta estructura productiva podían atender a la gran demanda de madera de aquel momento, ya fueran vigas o tablones para la construcción, la 
entibación de minas y el ferrocarril, o tablillas para la fabricación de envases destinados a la exportación, así como maderas de mayor calidad para otros usos. Durante este periodo, la sociedad tuvo que superar varias dificultades, como las huelgas derivadas de las políticas laborales y los cambios sociales o el estallido de la guerra europea que, aunque afectó negativamente al comercio de este sector en un primer momento, a la larga supuso un beneficio en las exportaciones debido a la escasez de madera extranjera ${ }^{6}$.

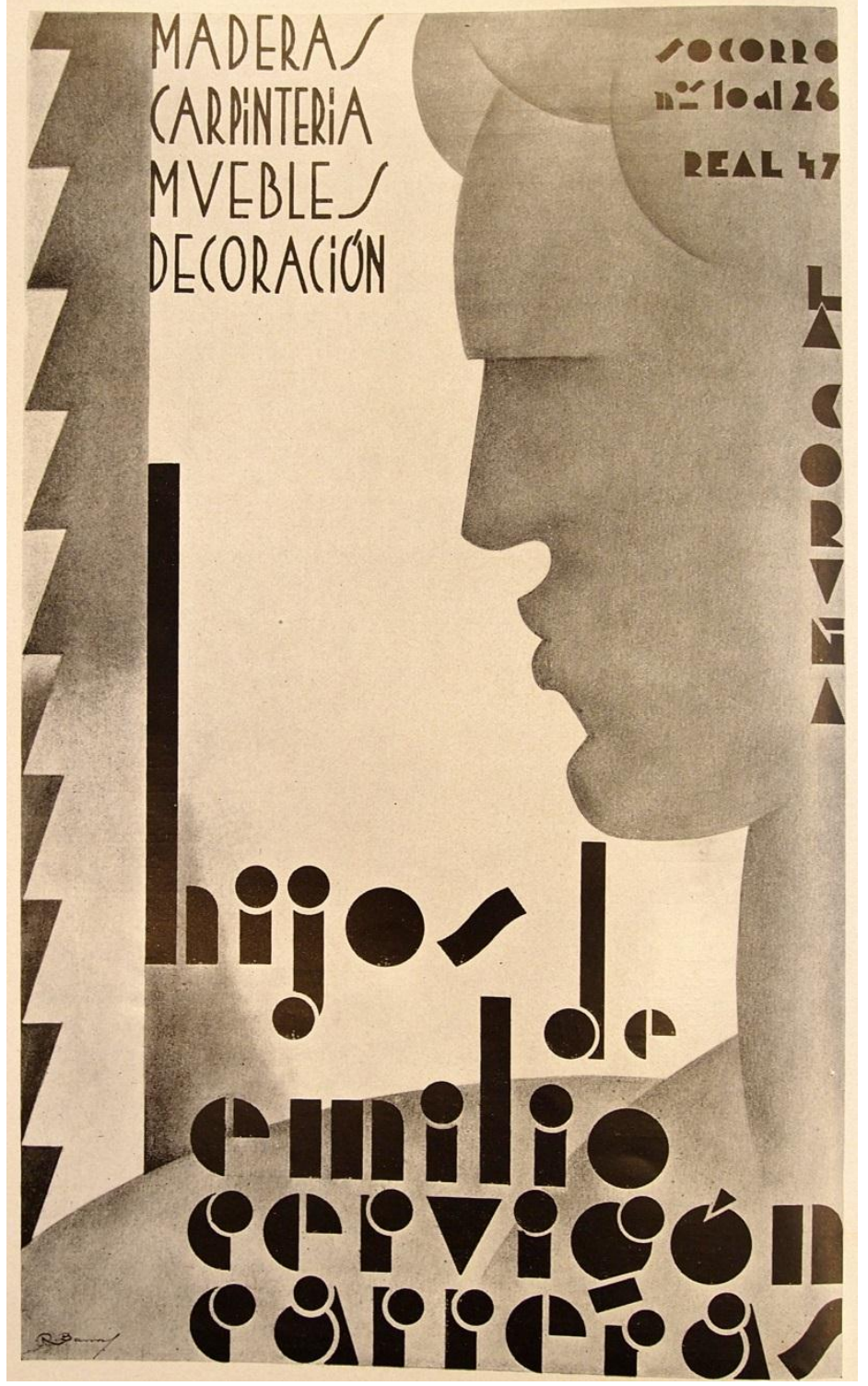

Fig. 2. Anuncio publicitario de la casa Hijos de Emilio Cervigón Carreras. El libro de Oro de Galicia, 1932.

En 1917 se disolvió la sociedad por la muerte de Emilio, pero tres años más tarde sus hijos José, Emilio y Ricardo crearon Hijos de Emilio Cervigón Carreras, una nueva razón social bajo la que continuarían con las mismas líneas de negocio abiertas por sus antecesores. El auge de la construcción en A Coruña impulsará el crecimiento de la empresa y dará lugar a una mayor especialización en el sector del mueble y la decoración, alcanzando un especial reconocimiento por la nueva sección de muebles de lujo a medida y realizados en una gran variedad de 
maderas exóticas que importaban de América, África, Filipinas y el Norte de Europa. Durante este periodo la imagen de la empresa y de sus productos se adaptó a las últimas tendencias en materia de diseño, que sus propietarios conocían a través de publicaciones y viajes ya que, como su abuelo, eran asiduos visitantes de ferias y exposiciones, a diferencia de la mayoría de sus competidores locales ${ }^{7}$. (Fig. 2)

La modernización de la maquinaria del aserradero y los talleres, que les permitía fabricar muebles en serie y en grandes cantidades, fue clave para poder presentarse a los concursos de amueblamiento que se convocaban, como el de las nuevas butacas del Teatro Rosalía Castro o algunos centros escolares, cuyo mobiliario debía adaptarse a los estándares fijados a nivel nacional ${ }^{8}$. Para sus muebles de gama alta adoptaron las líneas geométricas y la estética sofisticada del Art Déco que imperaba en Europa y América tras la Exposición de Artes Decorativas de París de $1925^{9}$. Esta imagen de modernidad encajaba en el programa decorativo diseñado para el nuevo Palacio Municipal coruñés, por lo que se adjudicó a esta casa el concurso para el amueblamiento artístico del salón de sesiones y la alcaldía oficial; este encargo obligó a ampliar la nómina de profesionales cualificados en ebanistería y talla en madera, como el escultor gallego José Juan y el tallista húngaro Ladislao Stern Fleiner ${ }^{10}$.

Precisamente, el alto nivel del trabajo de ebanistería que ofrecía la casa Cervigón se convirtió en una de las señas de identidad de la firma en este periodo y ese es también el motivo por el que sus muebles tuvieron un gran éxito entre la clientela más selecta de la nueva burguesía de los años veinte, que quería distinguirse con productos exclusivos y vanguardistas pero sin renunciar a la calidad y la tradición. Resulta llamativo que, teniendo como referencia a los grandes nombres del mueble francés de la época y sus patrones comerciales, Cervigón no firmase sus muebles de lujo, lo que denota que se seguían considerando más carpinteros que artistas ${ }^{11}$.

A pesar del éxito y el prestigio adquiridos, esta etapa empresarial no estuvo exenta de dificultades, siendo la más determinante el incendio de la fábrica el 13 de noviembre de 1928, cuyas pérdidas supusieron un lastre que se agravó por las huelgas y la gran depresión de principios de los treinta ${ }^{12}$. Los ajustes económicos y de personal no evitaron la liquidación de la empresa en 1947 ante la falta de apertura y dinamismo que presentaba la situación económica española. Poco después, Ricardo y Emilio retomaron la actividad por separado y con distinta fortuna; Ricardo consiguió cierto éxito gracias a la diversificación, pero, de nuevo, otro incendio acabaría definitivamente con la historia de este imperio de la madera en 1971.

\section{La modernidad de un despacho clásico}

De los tres conjuntos de amueblamiento encargados a Hijos de Emilio Cervigón Carreras para la vivienda del Cantón Pequeño $\mathrm{n}^{0} 22$, uno de ellos -el comedor- se ha perdido y tampoco disponemos de información sobre su aspecto o los elementos que lo integraban ${ }^{13}$. Para el dormitorio, que sí se conserva, se 
realizaron varias piezas en caoba: una cama con un gran cabecero circular, dos mesitas, un armario y un tocador con espejo. En el amueblamiento de los nuevos hogares, el comedor y el dormitorio matrimonial eran dos piezas básicas, no así el despacho, que era, y sigue siendo, un elemento de prestigio poco habitual en las viviendas y que habitualmente estaba vinculado a la actividad profesional liberal o comercial del propietario. El padre de familia desarrollaba aquí su trabajo y recibía a los clientes, proveedores y amigos, por lo que debía ubicarse cerca de la entrada y las salas de recepción ${ }^{14}$. Era el espacio masculino de la vivienda, el santuario del dueño de la casa, y a él le correspondía elegir el mobiliario, que debía ser sencillo y severo, sin perjuicio del posterior toque femenino para incluir objetos prácticos y bellos ${ }^{15}$.

El despacho encargado a la casa Cervigón se compone de una mesa escritorio, un sillón y un armario biblioteca, tipologías esenciales y características de un gabinete de trabajo. En las tres piezas se utilizó madera de caoba maciza para las estructuras e interiores, mientras que las superficies exteriores están chapeadas en raíz de madroño ${ }^{16}$. La combinación de maderas nobles y exóticas confiere al conjunto cualidades decorativas y un aspecto lujoso que se aprecian con más nitidez ante a la simplicidad de las formas y la composición, a base de volúmenes geométricos. (Fig. 3)
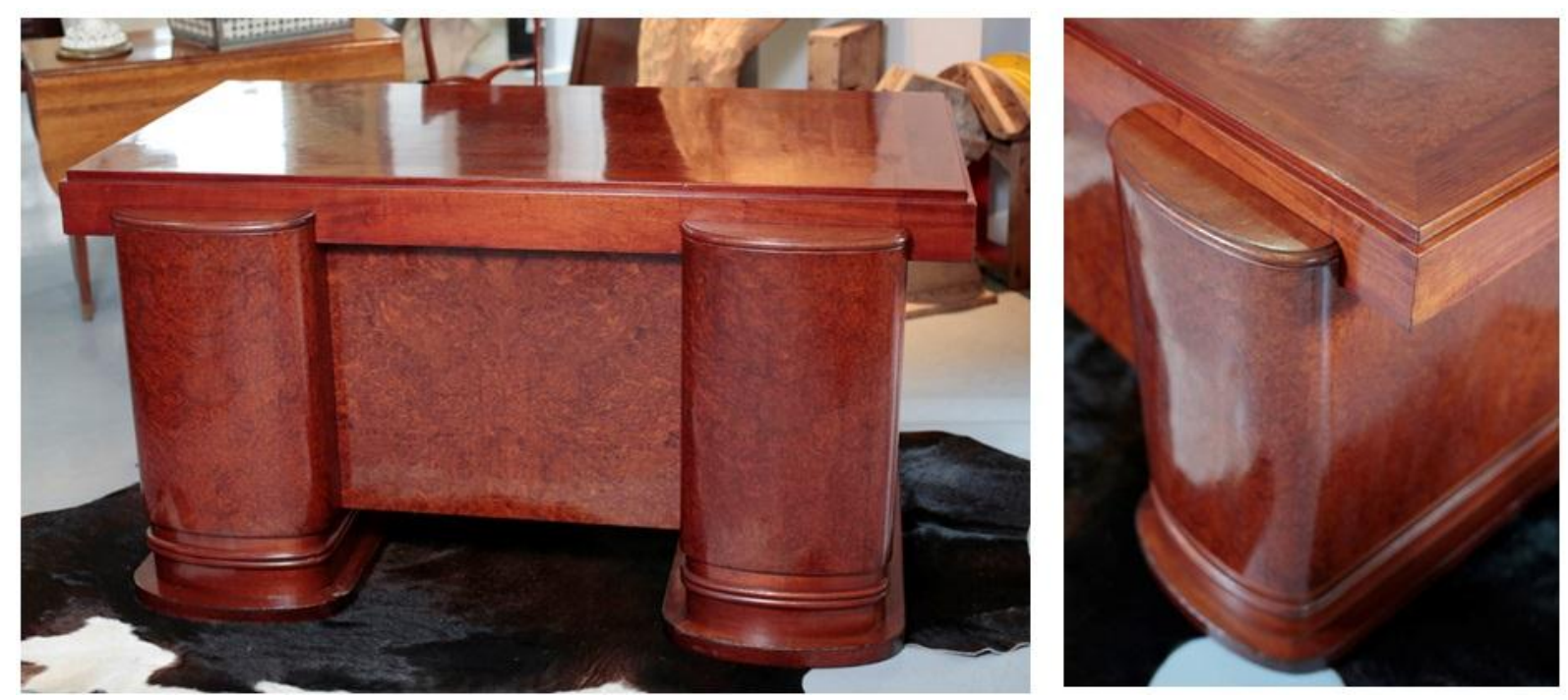

Fig. 3. Mesa escritorio de caoba y raíz de madroño. 95 x 150 x 78 cm. Hijos de Emilio Cervigón Carreras, La Coruña, c. 1931. Fotografías de Ana Gándara.

El tablero de la mesa es rectangular con tapa de raíz de madroño y un marco de caoba en el que se aloja un cajón con cerradura. Va encajado en dos cuerpos laterales de frentes redondeados y puertas planas en el lado opuesto -con cerradura para acceder a las baldas del interior- que se apoyan sobre zócalos de caoba con molduras y una base ligeramente mayor. La chapa de raíz de madroño cubre el frente, los laterales y las puertas de estos dos elementos, así como el panel frontal que los une. Un esquema similar al de la mesa, pero a mayor escala, es el que encontramos en el armario librería de tres módulos. En este caso los frentes curvos de los laterales son dos puertas y el cuerpo central también es un 
espacio de almacenamiento, de forma que solo se deja una balda a la vista para libros u objetos decorativos. Esta composición, en la que predominan los espacios cerrados, respondía a las necesidades del destinatario que, aunque ingeniero industrial de profesión, administraba las propiedades que la familia tenía en Argentina, y necesitaría archivar documentos y almacenar todo tipo de papeleo. La funcionalidad está presente hasta en los mínimos detalles, como el pequeño espacio destinado a mueble bar que encontramos en el interior y que está pensado para las ocasiones en las que el despacho es usado como lugar de recepción. (Fig. 4)

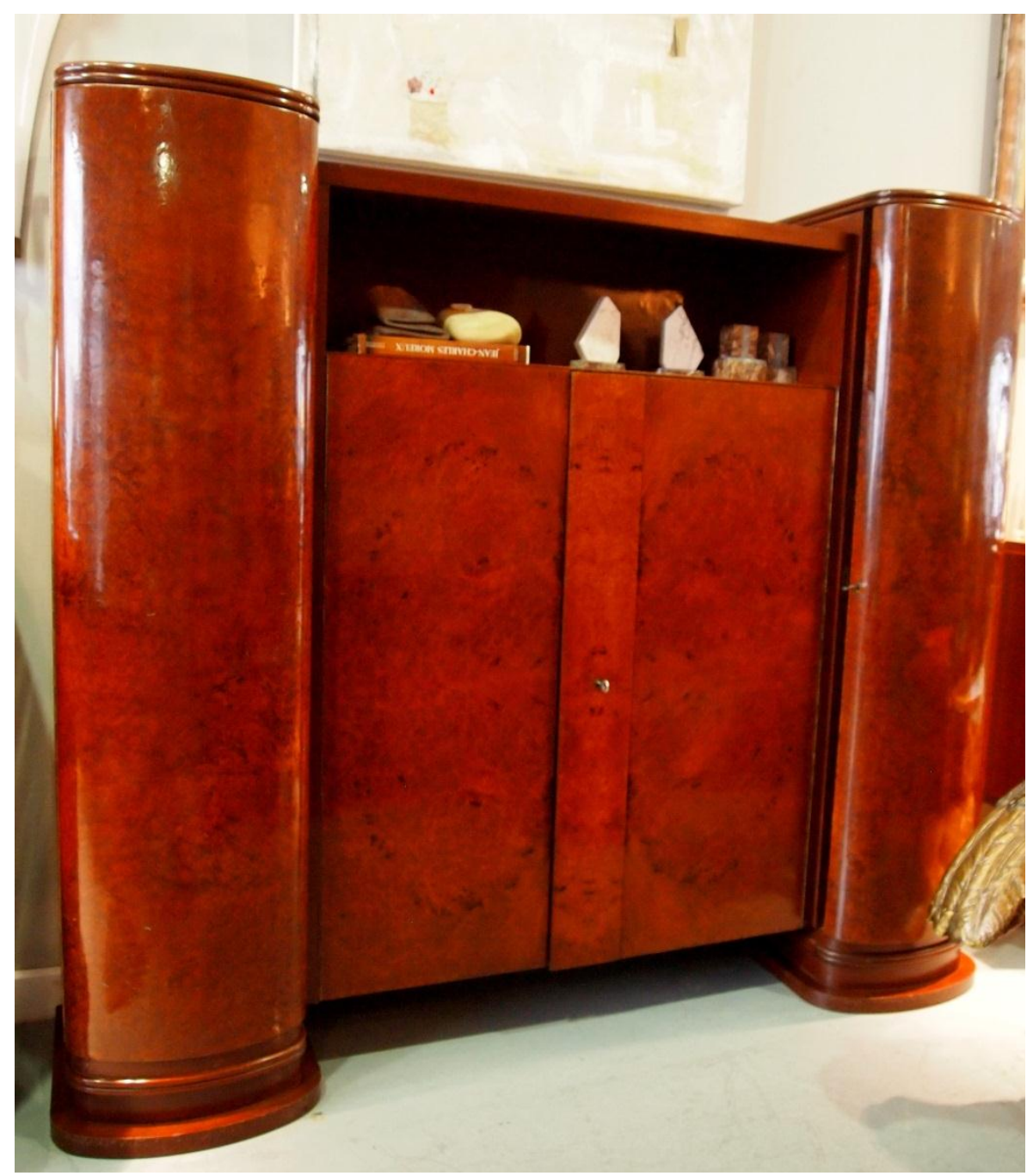

Fig. 4. Armario librería de caoba y raíz de madroño. 170 x 191 x $42 \mathrm{~cm}$. Hijos de Emilio Cervigón Carreras. La Coruña, c. 1931. Fotografía: Isabel Barro.

Lo más destacable de estos muebles es su configuración a base de volúmenes geométricos muy definidos y rotundos, que se aligeran mediante el movimiento de planos y las diferencias de alturas e introduciendo espacios vacíos. Las superficies planas y los ángulos rectos ceden protagonismo a la curva, que se destaca y se trabaja con especial esmero como muestra de la destreza en la ebanistería, que confiere a los muebles de Cervigón el aspecto de calidad y solidez que les caracteriza y que permanece con el paso del tiempo. 
El estilo Renacimiento, tradicionalmente utilizado para amueblar estos espacios masculinos, se sustituye aquí por un mobiliario sobrio, carente de talla o decoración añadida, y en el que prima el orden a pesar de su composición novedosa. Las reminiscencias clásicas y su apariencia robusta aportan la solemnidad necesaria para que pueda considerarse idóneo, igualmente, para estos ámbitos.

La estética Art Déco encontró su público entre la cosmopolita burguesía coruñesa, ávida de incorporar las novedades europeas, pero solo unos pocos podían acceder a estos productos exclusivos de factura impecable y que mantenían la esencia de la tradición y la intemporalidad.

\title{
NOTAS
}

\begin{abstract}
${ }^{1}$ Según los planos presentados por el arquitecto Pedro Mariño en septiembre de 1926, se trataba de viviendas amplias y luminosas, todas ellas con ascensor y calefacción. El tercer y cuarto pisos se comunicaban por una escalera interior configurando una única vivienda, en cuya planta inferior se hallaban las salas de recepción, un gran comedor y un despacho junto a la galería con vistas al jardín posterior. Ver, Archivo Municipal de A Coruña (en adelante A.M.C.), A. C. Obras Mayores, C- 271 (10): Reforma de las plantas del proyecto en ejecución de la casa $N^{\circ} 22$ del Cantón Pequeño de esta ciudad propiedad de Don Manuel Andrade.

${ }^{2}$ Información proporcionada por Julio Andrade, uno de los descendientes de esta familia, en una entrevista realizada en A Coruña el día 18 de julio de 2014.

${ }^{3}$ Ver ALONSO ÁlVAREZ, Luis; LINDOSO TATO, Elvira y VILAR RODRÍGUEZ, Margarita, Construyendo empresas: la trayectoria de los emprendedores coruñeses en perspectiva histórica, 1717-2006, Vol. I, A Coruña, Confederación de Empresarios de La Coruña, 2008, pp. 143-157. En esta obra se recorren los más de ciento cuarenta años de historia de esta empresa familiar, junto a la de empresarios destacados de otros sectores de la economía coruñesa de los siglos XIX y XX. Esta ha sido la fuente principal para nuestro estudio sobre la actividad de las diferentes generaciones de la familia Cervigón. A partir de esta obra también se han publicado en la prensa local algunos artículos que resumen la historia de la empresa, como "Cervigón, un imperio de la madera", en La Opinión. A Coruña, 8 de marzo de 2009, $<$ http://www.laopinioncoruna.es/economia/2009/03/08/cervigon-imperio-madera/266764.html> [Consulta: 23 de noviembre de 2014].

${ }^{4}$ Los Libros de Actas del Ayuntamiento coruñés de los años 1862, 1866 y 1875 mencionan que la fábrica contaba con ocho obreros, máquina de vapor de 12 c. v. y que su nombre comercial era El Sol, según FERNÁNDEZ CAAMAÑO, José Manuel, La Coruña vista desde sus libros de actas, II, Madrid, Vision Net, 2004, pp. 259 y 260. "En la misma calle del Socorro existe otra fábrica de serrar maderas, perteneciente a los Sres. De Cervigón: la máquina es de vapor de fuerza de doce caballos. En este establecimiento hay también fábrica de puntas de París, y almacén de maderas del Reino y estrangeras (sic)", en COUMES-GAY, Antonio, Guía de La Coruña, La Coruña, Imprenta de Domingo Puga, 1877, p. 42. Ver también ARMESTO, Victoria, Verbas Galegas, La Coruña, Galaxia, 1973, p. 54.

${ }^{5}$ ALONSO ÁlVAREZ, Luis (et alt.), Construyendo empresas..., cit, p. 145. Cerca de La Gaiteira se encontraba la refinería de su propiedad, según BARREIRO FERNÁNDEZ, José Ramón, Historia de la ciudad de La Coruña, La Coruña, La Voz de Galicia, 1986, p. 370. En 1891 Eduardo M. Cervigón aparece entre los quince mayores contribuyentes de la ciudad, según FERNÁNDEZ CAAMAÑO, José Manuel, La Coruña vista..., cit., p. 216. Una breve semblanza sobre su trayectoria se ofrece en "Cómo hacerse millonario vendiendo clavos" en La Voz de Galicia, 13 de noviembre de 2002, $<$ http://www.lavozdegalicia.es/hemeroteca/2002/11/13/1321784.shtml> [Consulta: 23 de noviembre de 2014].

${ }^{6}$ Ver en MIRÁS ARAUJO, Jesús, Continuidad y cambio en la España urbana en el periodo de entreguerras. Análisis de una ciudad española, A Coruña, Netbiblo, 2007, p. 70-71. Para ampliar la información sobre el sector maderero gallego consultar CARMONA BADÍA, Xoán y NADAL OLLER, Jordi, El empeño industrial
\end{abstract}


de Galicia: 250 años de historia (1750-2000), A Coruña, Fundación Pedro Barrié de la Maza, 2005, pp. 166-170.

${ }^{7}$ Información proporcionada por Cristina Cervigón Prieto el 21 de noviembre de 2012.

${ }^{8}$ Ver BARRO REY, Isabel, "La decoración a escena: caracterización de las casas de decoración coruñesas a través de las reformas del Teatro Rosalía Castro", en Res Mobilis. Revista internacional de investigación en mobiliario y objetos decorativos, Vol. 2, Núm. 2, Oviedo, 2013, pp. 168-177. Ver también A.M.C., A. C., Servicios. Educación, C- 2409.

${ }^{9}$ Para comprender la influencia del Art Déco en la arquitectura y el panorama artístico coruñés, ver GARRIDO MORENO, Antonio, "Aproximación a la primera arquitectura déco en Galicia: el modelo corunés", en Quintana: revista de estudios do Departamento de Historia da Arte, núm. 1, Santiago de Compostela, 2002, pp. 225- 239. Según el autor, la temprana presencia de la nueva estética en A Coruña puede atribuirse al ambiente cultural progresista, representado por la revista Alfar, y a la favorable acogida por parte de los arquitectos locales, que adoptaron este estilo como vía de transición hacia la funcionalidad del racionalismo. También se hace referencia al mobiliario del Palacio Municipal realizado por la casa Cervigón como ejemplo de Art Déco en interiores.

10 También contaron con diseñadores como Rafael Barros Merino, que más tarde sería asesor artístico del Ayuntamiento y profesor de la Escuela de Artes y Oficios Artísticos de A Coruña. Ver BARRO REY, Isabel, "Una manifestación de progreso e identidad. La decoración de interiores en el ayuntamiento de A Coruña", en Viejos y nuevos espacios públicos para la decoración de interiores en España”, Gijón, Editorial Trea, 2012, pp. 133-174. Poco después se encargarán también de amueblar la nueva sede del Colegio Oficial de Notarios con un mobiliario más vanguardista.

${ }^{11}$ Según el testimonio del restaurador David Henson, conocedor de los muebles de Cervigón por haber trabajado con ellos en numerosas ocasiones, no existe ningún tipo de marca que los identifique, pero su filiación es inconfundible por la factura y la calidad de las maderas. Entrevista realizada el 4 de noviembre de 2014.

12 "En la fábrica de muebles de los Hijos de Cervigón en la calle de Socorro, se produjo un gran incendio que destruyó totalmente el edificio y las existencias. El fuego se propagó al Asilo municipal, contiguo, teniendo que ser trasladados los ancianos y los niños acogidos a las escuelas públicas próximas. El incendio continua, por la gran cantidad de madera almacenada. Las causas del siniestro se ignoran, y las pérdidas se calculan en más de un millón de pesetas". $A B C$, Madrid, 14 de noviembre de 1928, p. 28.

${ }^{13}$ Hay otros testimonios materiales que sugieren una mayor intervención de esta firma en la decoración. Según Ana Gándara, anticuaria especializada en Art Déco, el parquet de la vivienda, con un dibujo geométrico en madera de roble, ébano y caoba, probablemente también fue realizado por la casa Cervigón, teniendo en cuenta su analogía con otros trabajos de la firma. En la vivienda había otros muebles auxiliares realizados en las mismas maderas y con las características de estilo y factura propias de las obras de Cervigón. Entrevista realizada el 16 de julio de 2014 en A Coruña.

14 ELEB, Monique y DEBARRE, Anne, L'Invention de l'habitation moderne. Paris 1880-1914, Paris, A.A.M./Hazan, 1995, pp. 24-26. También servía como sala de fumar para los hombres.

${ }^{15}$ BLASCO ESQUIVIAS, Beatriz (dir.), La casa. Evolución del espacio doméstico en España, Vol. 2, Madrid, El Viso, 2006, pp. 45-46. Ver también BARRO REY, Isabel, "Los interiores domésticos de Julio Galán Carvajal en A Coruña (1901-1911)”, en Res Mobilis, Vol. 3, Núm. 3, 2014, pp. 19-41.

${ }^{16}$ David Henson nos amplía la información sobre la madera de madroño (en inglés, madrona) usada en el chapeado, que en el caso que nos ocupa pertenece a la especie arbutus menziesii, procedente de América del Norte, mientras el madroño que se encuentra en España es arbutus unedo. Ver nota 10.

Fecha de recepción: 15 de octubre de 2014

Fecha de revisión: 5 de diciembre de 2014

Fecha de aceptación: 13 de enero de 2015 